both physical and psychosocial domains. In subjects who are not receiving DMARD therapy, anakinra leads to improvements in health-related quality of life.

\section{SAT0246 CHARACTERISING THE EFFECTS OF ANAKINRA THERAPY ON FUNCTIONAL STATUS OF PATIENTS WITH RHEUMATOID ARTHRITIS USING METHOTREXATE}

${ }^{1}$ SB Cohen, ${ }^{2} \mathrm{JM}$ Woolley, ${ }^{2} \mathrm{WW}$ Chan. ${ }^{1}$ Department of Rheumatology, St. Paul Medical Center, Dallas, USA; ${ }^{2}$ Amgen Inc., Thousand Oaks, USA

10.1136/annrheumdis-2001.882

\section{Background}

Objectives To characterise the effects of anakinra on the functional status of subjects with rheumatoid arthritis using methotrexate.

Methods In a large multidose placebo controlled study of anakinra in subjects with rheumatoid arthritis (RA), functional status was evaluated at baseline and after 24 weeks of therapy using the Health Assessment Questionnaire (HAQ). The HAQ includes questions designed to assess functional status as related to dressing and grooming (D\&G), arising (ARI), eating (EAT), walking (WLK), hygiene (HYG), reach (RCH), grip (GRP), and activities (ACT). Comparisons between Methotrexate (MTX) alone $(\mathrm{n}=$ $74)$, and anakinra $+\operatorname{MTX}(\mathrm{n}=131)$, based on the combined data for the two highest doses $(1 \mathrm{mg} / \mathrm{kg}$ and $2 \mathrm{mg} / \mathrm{kg})$, were analysed using change in scores from baseline through 24 weeks.

Results Change scores for all eight of the HAQ scales (Table 1) were positive, and six were statistically significant. The biggest effects were seen in reach, hygiene, and eating, while walking showed the smallest effect. Furthermore, by the end of the study a greater percentage of subjects on anakinra + MTX reported functionality without any difficulty, as compared to those on MTX alone (data not shown).

\begin{tabular}{|c|c|c|c|c|c|c|c|c|}
\hline \multicolumn{3}{|c|}{$\begin{array}{l}\text { Abstract SAT0246 Table } 1 \\
\text { baseline to week } 24\end{array}$} & \multicolumn{6}{|c|}{ Mean change in HAQ scales from } \\
\hline & D\&G & ARI & EAT & WLK & HYG & RCH & GRP & ACT \\
\hline Anakinra + MTX & -0.38 & -0.37 & -0.40 & -0.19 & -0.23 & -0.29 & -0.45 & -0.42 \\
\hline Placebo + MTX & -0.09 & -0.16 & -0.07 & -0.12 & 0.14 & 0.07 & -0.19 & -0.19 \\
\hline Difference & -0.29 & -0.21 & -0.34 & -0.07 & -0.36 & -0.36 & -0.26 & -0.23 \\
\hline P-Value & .011 & .043 & .004 & .515 & .019 & .005 & .025 & .052 \\
\hline
\end{tabular}

Conclusion Subjects receiving at least $1 \mathrm{mg} / \mathrm{kg}$ of anakinra showed statistically significant improvements in functional status as measured by the HAQ. Improvements were evident in almost all of the HAQ scales. Anakinra improves functional status across a wide range of domains in subjects with rheumatoid arthritis.

\section{SAT0247 A CHINESE VERSION OF THE RHEUMATOLOGY ATTITUDES INDEX IS A VALID AND RELIABLE MEASURE OF LEARNED HELPLESSNESS IN SLE PATIENTS}

${ }^{1} \mathrm{KY}$ Fong, ${ }^{1} \mathrm{f}$ Thumboo, ${ }^{2} \mathrm{PH}$ Feng, ${ }^{3} \mathrm{SP}$ Chan, ${ }^{4} \mathrm{ML}$ Boey, ${ }^{1} \mathrm{ST}$ Thio. ${ }^{1}$ Medicine (Rheumatology), National University of Singapore; ${ }^{2}$ Rheumatology; ${ }^{3}$ Clinical Epidemiology, Tan Tock Seng Hospital; ${ }^{4}$ Rheumatology, Mount Elizabeth Hospital, Singapore, Singapore
Background The Rheumatology Attitudes Index is a widely used measure of learned helplessness ( $\mathrm{LH})$, an acquired pattern of behaviour in which, as a result of adverse past experiences, individuals believe their efforts will be ineffective. $\mathrm{LH}$ is associated with poorer quality of life in a variety of rheumatic diseases, and with increased morbidity and mortality in patients with rheumatoid arthritis. Despite the importance of learned helplessness in rheumatic conditions, there are no validated measures of this construct in Chinese or other Asian languages.

Objectives To assess the internal consistency, reliability and construct validity of a Chinese translation of the Rheumatology Attitudes Index (CRAI) and it's Helplessness (CHS) and Internality (CIS) subscales.

Methods The source English RAI was translated into Chinese using standard techniques for cross-cultural adaptation. Chinesespeaking SLE patients completed identical, self-administered Chinese questionnaires containing the CRAI and assessing demographic and socio-economic variables twice within a 2 week period. SLE related activity, damage and quality of life were assessed using the BILAG, SLICC/ACR Damage Index and SF-36 Health Survey respectively. Scale psychometric properties were assessed through factor analysis, Cronbach's alpha, intra-class correlations and quantifying test-retest differences. Relationships between the CRAI, its subscales and external variables (knowngroups construct validity) were studied using Spearman's rank correlation.

Results Active disease and disease related damage were present in $52.2 \%$ and $49.3 \%$ of 69 Chinese speaking SLE patients with a median disease duration of 4.7 years. Internal consistency and reliability were acceptable, with Cronbach's a for the CHS, CIS and CRAI being 0.70, 0.69 and 0.74 respectively, mean differences in test-retest scores being $0.47,0.55$ and 0.93 points respectively (representing 1.6 to $2.4 \%$ of possible scale ranges) and intra class correlations ranging from 0.72 to 0.83 . Factor analysis identified 2 major factors corresponding to the HS and IS subscales of the CRAI. Eight of 10 hypotheses relating the CRAI and CHS to demographic, disease and quality of life variables were confirmed, supporting the construct validity of these scales. Conclusion The CRAI and it's helplessness subscale are valid and reliable measures of learned helplessness in Chinese speaking SLE patients.

\section{SAT0248 PHARMACOEPIDEMIOLOGICAL PROFILE OF PATIENTS TREATED FOR OSTEOARTHRITIS}

${ }^{1}$ F Marchetta, ${ }^{2}$ E Degli Esposti, ${ }^{3} S$ Buda. ${ }^{1}$ Clinical Phamacology - Clinical Epidemiological Consultant, Azienda Ospedaliera S. Orsola-Malpighi, Bologna, Italy; ${ }^{2}$ Unit for the Evaluation of Processes and Outcomes, Ravenna Local Health Unit, Ravenna, Italy; ${ }^{3}$ Health, Economics \& Outcomes Researches, CliCon Srl, Ravenna, Italy

\subsection{6/annrheumdis-2001.884}

Background Public health decision makers and healthcare payers have become increasingly interested in collecting epidemiological and economic information to improve the allocation of limited health care resources.

Objectives The purpose of this preliminary study was to describe a pharmacoepidemiological profile of patients treated for osteoarthritis (OA) by 21 general practitioners in the Local Health Unit (LHU) of Ravenna.

Methods Retrospective chronological reading of all prescriptions written for OA. All patients receiving a prescription for a NSAID or rofecoxib were included. The computerised data file, housed in the LHU of Ravenna since January 1996, contains all 